\title{
MEMÓRIA E CIDADE ATRAVÉS DE BENJAMIN E BAUDELAIRE
}

\author{
Abraão Carvalho
}

\author{
RESUMO
}

Através de um estudo da condição histórica das grandes cidades, levadas adiante pelo filósofo Walter Benjamin, através de seu célebre ensaio "Sobre Alguns Temas em Baudelaire", e sua reflexão em torno do tema da memória do indivíduo urbano a partir da noção de memória involuntária, procuramos estabelecer um nexo entre as proposições benjaminianas acerca da cidade moderna, aliada a um exercício de interpretação de alguns poemas de Baudelaire, dentre eles, "Correspondências", e "Os sete velhos", ambos do livro "As flores do mal", além de um diálogo com o poema em prosa "O mau vidraceiro", do livro de contos do poeta francês "Pequenos poemas em prosa".

Palavras-chave: Walter Benjamin. Memória. Cidade. Baudelaire.

\section{MEMORY AND CITY THROUGH TO BENJAMIN AND BAUDELAIRE}

\begin{abstract}
Through a study of the historical condition of the big cities, established by the philosopher Walter Benjamin, through his celebrated essay About some themes in Baudelaire, and its reflection on the theme of urban individual memory, marked by involuntary memory notion, seek establish a link between the Benjamin propositions about the modern city, combined with an exercise of interpretation of some poems of Baudelaire, among then, Correspondences and The seven old, both the book The Flowers of evil, and a dialogue with the prose poem The bad glazier, the storybook french poet Small poems in prose.
\end{abstract}

Keywords: Walter Benjamin. Memory. City. Baudelaire. 


\title{
1 Fragmentos de história no modo próprio de memória do habitante das grandes cidades: memória involuntária
}

\author{
"faz tempo, que me esqueço das horas \\ e as horas vão matando o que penso \\ o tempo trás a história do mundo nas costas \\ tudo isso vem no sopro do vento" \\ Jorge Du Peixe
}

Alguns dos traços que afetam o modo de vida urbano estão situados na maneira como as relações entre memória e história se dão. Com as transformações radicais ocorridas principalmente desde o século XIX, de ordem espacial, demográfica e cultural, e que de certo abriram espaço para o surgimento da metrópole moderna, a modalidade histórica de memória própria ao habitante dos grandes centros e subúrbios urbanos contemporâneos, fora também alterada abruptamente.

Nesta direção, os traços que irão atravessar a modalidade histórica de memória do habitante urbano terão como aspecto marcante a crise da experiência cultural coletiva, única capaz de criar uma memória coletiva, que sucumbe, pois, em uma "vivência" desvinculada de qualquer tradição. Fragmentos de memória irão marcar o modo de vida que no pensamento de Benjamin recebe o nome de "vivência", pois não é da tradição que o habitante urbano participa. Com efeito, os conteúdos da memória individual não se entrelaçam com os da memória coletiva, pois o passado não se encontra na tradição, esta encontra-se em crise, mas por outro lado, no espaço de vivência, em algum objeto, em alguma fotografia, rua, e em certa medida, na metrópole contemporânea.

Tendo em perspectiva as transformações abruptas pelas quais o século XIX atravessou, principalmente de ordem espacial e demográfica, é que podemos situar um dos grandes paradoxos da vida urbana, isto é, se por um lado a cidade e seus subúrbios concentram cada vez mais pessoas em seu espaço, por outro, a possibilidade de inserir-se em uma tradição cultural, capaz de criar um fio de continuidade entre as gerações ao menos provisório historicamente, nos é crescentemente distante, sendo o culto religioso tradicional portador de verdades arcaicas, um dos espaços coletivos depositários da abertura da possibilidade de 
acolher ou mesmo oferecer um salvo conduto para esta experiência em crise.

Na perspectiva de Benjamin, quando da tentativa de interpretação das Flores do Mal de Baudelaire, é no culto que se abriga a experiência desvinculada de qualquer tradição, e sobretudo em crise, como afirma o ensaísta alemão acerca das Correspondências. Sendo este poema para Benjamin o que concentra o significado de um modo de vida que pode ser caracterizado enquanto "uma experiência que procura se estabelecer ao abrigo de qualquer crise. E somente na esfera do culto ela é possível" (BENJAMIN, 1994, 132).

Daí Benjamin nomear um dos traços que afetam e atravessam a modalidade histórica de memória própria à vivência urbana de memória involuntária. Pois se da crise da experiência cultural coletiva, desvinculada de uma tradição, resulta a vivência com momentos raros de criação de laços culturais e sociais com os demais passantes da cidade, de tal modo que não é possível também uma memória coletiva na qual se insere a memória individual, daí a modalidade histórica de memória própria a esta vivência estar intimamente relacionada com o seu espaço, isto é, a cidade contemporânea ocidental. O que resulta na íntima relação entre memória, cidade e história.

É nas ruas, nas calçadas, nas praças, nos teatros, nos cinemas, nas escolas, no interior das moradias, nas galerias, nos veículos de transporte, nos emblemas da vida urbana, que o habitante urbano involuntariamente estabelece vínculos fragmentados com o seu passado, pois é um "Trabalho perdido procurar evocálo, todos os esforços de nossa inteligência permanecem inúteis. Está ele oculto, fora do seu domínio e do seu alcance, nalgum objeto material (na sensação que nos daria esse objeto material) que nós nem suspeitamos", como o afirma Proust (PROUST, 45).

Esta demarcação da noção de memória involuntária na acepção benjaminiana, ambientada no contexto da crise de experiência do habitante das cidades modernas, reflete de maneira acentuada o aspecto fragmentário da memória que cada vez mais está relacionada à rememoração particular. No artigo La mémoire de l'histoire chez Proust et Benjamin (2009), de Olivier Clarinval, esta investigação no modo de memória associada ao modo de percepção do habitante urbano da cidade moderna se trata de "una recherche... essentiallement sur la 
mémorie individualle, et une prise de conscience d'une période histórique" (CLARINVAL, 2009, 994) ${ }^{1}$.

Segundo Clarinval, a memória tem a capacidade de apreender o real, não de modo uniforme, contudo lhe é conferido este privilégio, e justo neste ponto, o autor retoma a distinção dos modos da memória indicados por Proust: "Si la mémoire este capable d'enrichir l'appréhension du réel, elle n'en est pas uniforme pour autant. II faut ici introdure une distinction capitale, selon Proust, entre deux types de remémorations: la mémórie volontarie et involontaire" ${ }^{2}(C L A R I N V A L, 2009,996)$. A memória voluntária se articula em maior medida com a memória histórica, de uma cultura, de um grupo, de um povo, de tal modo que tal tipo de memória é mediada por uma ação cognitiva, orientada e conduzida pela volição, neste sentido pontua o autor: "la mémoire volontarie, la mémoire de l'intelligence" ${ }^{3}$ (CLARINVAL, 2009, 996).

Por outro lado, a memória involuntária, ao passo que está precisamente associada à memória individual e interior, preserva a possibilidade de ser mediada não por uma ação cognitiva que através da vontade promove a articulação com o tempo da memória histórica que é tomada como memória voluntária. Em outra natureza e distinção, a memória involuntária apresenta um traço primordialmente perceptivo e subjetivo, de modo que o acontecimento de tal modo de memória, é transformado através do tempo de acordo com as nuanças sensoriais às quais está sujeito o habitante da urbe moderna no contexto da vivência na acepção benjaminiana, e através do percurso do convívio urbano propriamente dito.

De acordo com Clarinval: "La memóire involontarie, par contre, est issue d'un oubli, de ce que le regard conventionnel a depuis longtemps réprimé; elle peut donc engendrer une transformation, avec elle le temps devient um facteur producteur"4 (CLARINVAL, 2009, 997). O autor demarcar também, de acordo com nossa leitura, que o objeto da memória involuntária não está associado à História oficial, o que

\footnotetext{
"'Uma pesquisa essencialmente sobre a memória individual, e uma tomada de consciência de um período histórico" (tradução nossa).

${ }^{2}$ "Se a memória é capaz de enriquecer a apreenssão do real, ela não é uniforme no entanto. Aqui devemos introduzir uma distinção crucial, de acordo com Proust, entre dois tipos de rememoração: a memória voluntária e a involuntária" (tradução nossa).

3"a memória voluntária, a memória da inteligência" (tradução nossa).

4"A memória involuntária, por contraste, é o resultado de um esquecimento, que o olhar convencional depois de longo tempo reprimiu; ela pode portanto engendrar uma transformação, com ela o tempo torna-se um fator produtor" (tradução nossa).
} 
reforça o caráter individual da memória involuntária: "...est evident que les événements de l' Histoire officielle ne représentent pas l'object de recherche de la mémoire involontaire" ${ }^{5}$ (CLARINVAL, 2009, 997).

Neste sentido, o atravessar a rua entrelaça-se com o próprio acontecer deste modo de memória involuntária no contexto da cidade contemporânea ocidental. Este acontecimento, sobretudo realiza-se similarmente a um raio súbito, que se efetiva junto ao gesto mesmo de caminhar, no qual o passado encontra possibilidades de ecos no presente, sempre de maneira diferenciada através da memória involuntária, a qual se referem Proust e Benjamin. Dito de outro modo, é justamente neste horizonte entre o passado fragmentado do homem moderno ocidental e o acontecer da experiência de andar pelas ruas, o instante no tempo onde se efetiva o acontecimento súbito extraordinário que abre a possibilidade de olhar para o passado em estilhaços sempre de maneira diferenciada.

Ora, mas em que reside a importância deste modo de memória involuntária para o habitante das cidades modernas? Seguindo indícios encontrados na leitura de Clarinval, o acontecimento da memória involuntária instaura uma fenda destrutiva, e ao mesmo tempo criativa, na dinâmica do tempo da cidade moderna, oferecendo ao habitante da urbe, rememorações que podem ressignificar sua vivência, utilizando a acepção benjaminiana, transformando o tempo desta memória involuntária em um fator produtivo em relação ao presente, passado e futuro:

\begin{abstract}
La mémoire involontaire met au jour qualque chose d'oublié, de réprimé, de perdu. Le temps n'est plus ce vaisseau vide qui transporte sans cesse et unidirectionellement vers le futur et le progrès mais devient un facteur productif où le passé rencontre le présent dans une rencontre vertigineuse destructice du temps même ${ }^{6}$ (CLARINVAL, 2009, 1000).
\end{abstract}

Este traço de "recontre vertigineuse destructice du temps même", confere, segundo Clarinval, o aspecto dialético entre a leitura de Proust a respeito da memória involuntária, e sua apropriação por Benjamin quando este procura elucidar

\footnotetext{
${ }^{5}$ "é evidente que os eventos da História oficial, não representam o objeto da investigação da memória involuntária" (tradução nossa).

6"A memória involuntária descobre qualquer coisa de esquecido, de reprimido, de perdido. O tempo não é mais este navio que transporta de forma constante e unidirecionalmente para o futuro e o progresso, mais torna-se um fator produtivo, onde o passado encontra o presente em um encontro vertiginosamente destrutivo do tempo mesmo" (tradução nossa).
} 
outro modo de relação entre memória e história, de tal modo que o tempo cronológico histórico, no acontecimento da memória involuntária, seja transformado e reconectado, haja vista a necessidade de transformar a consciência do presente: "Le moment privilégié proustien et l'arrêt dialectique benjaminien se rejoignent dans una suspension du temps chonologique capable de transpercer et de transformer la conscience du présent"7 (CLARINVAL, 2009, 1001).

\section{0 mau vidraceiro de Baudelaire como alegoria do isolamento do habitante urbano e da vivência benjaminiana}

A estes traços que atravessam a modalidade histórica de memória própria ao habitante urbano, que se encontra com o seu passado fragmentado, na medida em que atravessa a cidade, acompanha a condição histórica da metrópole moderna ocidental, assentada em desigualdades sociais radicais.

Isto é, o modo de vida situado no espaço urbano moderno, encontra, em certa medida, a desrealização, negação, despotencialização, ou mesmo ruína da vida, na proporção em que a cidade, principalmente a partir do século XIX na Europa, altera abruptamente o seu índice populacional de maneira crescente. $\mathrm{E} o$ sistema de organização da vida e do trabalho da maioria dos habitantes no interior do espaço que nomeamos como cidade, consiste como resultante de uma sociedade assentada em abismos sociais radicalmente acentuados, sociedade esta, na qual a lógica da exploração extremada do homem e dos recursos naturais, movida sobretudo pela volúpia sedutora da acumulação de riquezas, permitiu às elites econômicas e políticas a hegemônica apropriação das técnicas de difusão cultural, como a imprensa escrita, a televisiva e a radiofônica, no decorrer do último século. O que de certo provocou uma crescente alienação de grande parte dos habitantes urbanos diante das transformações do período moderno.

Neste sentido, podemos situar também a alienação do homem moderno ocidental diante do trabalho, que segundo Marx, efetiva-se enquanto "desrealização

\footnotetext{
7"O momento proustiano privilegiado e o julgamento dialético benjaminiano se encontram em uma suspensão do tempo cronológico capaz de transparecer e de transformar a consciência do presente" (tradução nossa).
} 
do trabalhador", e não enquanto meio de autoconhecimento e criação autêntica diante da barbárie moderna, sendo tais formas de alienação do homem, diante da técnica e do trabalho, o que fomentou a continuidade de maneira acentuada, da desagregação social, espacial e cultural no âmbito do solo violento e hostil no qual se move a experiência urbana contemporânea e sobretudo brasileira.

Deste modo, é possível identificar que as transformações do mundo urbano moderno, provocaram um isolamento crescente do habitante sujeito a este modo de vida urbano. Dito de outro modo, isto significa dizer que as transformações que afetaram o habitante da cidade ocidental contemporânea, promoveram uma alteração radical na relação deste com os demais passantes que circulam por entre a multidão. O que isto significou precisamente? Que o habitante urbano depara-se com um contexto histórico no qual a experiência de sociabilidade cultural, é marcada não por uma experiência autêntica mas sobretudo por uma vivência.

No artigo As imagens da modernidade nos 'Quadros Parisienses' de Baudelaire e a relação com o caderno 'J-Baudelaire' de projeto das Passagens" (Cadernos Walter Benjamin, 2012), de Jorge Teodoro, encontramos esta demarcação do modo de vivência do habitante urbano marcado pela vivência. A partir de referências ao artigo de Bernardo Oliveira Baudelaide, Benjamin e a arquitetura D'As Flores do Mal, pontua Teodoro:

\footnotetext{
Perda da experiência autêntica (Erfahrung) e sua substituição por uma experiência pautada no choque com a multidão, apresentada como vivência (Erlebnis) típica do sujeito moderno. Como experiência autêntica, podemos entender aquela experiência transmitida em sentido pleno, compartilhada de maneira coletiva e socialmente. A vivência é a substituta da Erfahrung, de modo que se constitui como experiência determinante da sociedade capitalista... O sujeito no mundo moderno, determinado pelo processo de produção e pelo tempo reificado, encontra-se impossibilitado de desenvolver uma experiência autêntica, pois todas as experiências contidas nessa sociedade resumem-se às adiquiridas na vivência diária do contato com a máquina e nos choques com a multidão" (TEODORO, 2012, 46).
}

Neste sentido, certo modo de vida urbano encontra no aconchego de sua moradia, assim como no interior de seus carros particulares, algumas das possibilidades técnicas de comunicação com o outro e de acesso à informação, à mercadoria e à arte que se edifica a partir da reprodução técnica, tal como o cinema, abrindo, através da tecnologia, a possibilidade de conforto no seu refúgio particular, 
necessário ao seu modo de vida pobre em experiências comunicáveis autênticas, e fundamental, portanto, nesta medida, para o salvo conduto daquilo que Benjamin nomeou de "pobreza de experiência". Daí o ensaísta alemão afirmar que "O conforto isola" (BENJAMIN, 1994, 124), e sobretudo pode criar uma reação de certo modo violenta em relação ao outro, como narra Baudelaire no poema em prosa O mau vidraceiro.

Esta reação vai de encontro ao aparecer do outro, e ocorre desde a perspectiva da vivência urbana pobre em experiências comunicáveis, e nesta condição, por vezes concentra algo da ordem do violento. Segundo Baudelaire em um de seus Pequenos poemas em prosa, nomeado O mau vidraceiro, esta reação violenta do habitante urbano marcado pelo isolamento, consiste sobretudo em "uma espécie de energia que brota do devaneio e do tédio; e aqueles em quem ela se manifesta de maneira tão violenta são, em geral, ...os mais indolentes e os mais sonhadores entre os seres" (BAUDELAIRE, 1980, 31).

Deste modo, na perspectiva de Baudelaire, por meio do devaneio, do delírio e do tédio da vivência, como lado adverso e obscuro deste modo de vida urbano marcado pelo isolamento do qual afirma Benjamin, esta vivência desvinculada de uma tradição depositária de um campo de linguagem comum entre as gerações, por vezes e de maneira súbita, na figura deste habitante urbano alegorizado na literatura do poeta francês, encontra a forma de reagir de encontro aos demais passantes do solo urbano moderno, marcado por um modo violento de agir. $\mathrm{O}$ narrador, a partir dessa perspectiva, não hesita em afirmar que por diversas vezes pudera ser "vítima destas crises e destes impulsos, que nos autorizam a crer que malignos Demônios se infiltram em nós e nos induzem a realizar, à nossa revelia, os seus mais absurdos caprichos"(BAUDELAIRE, 1980, 32).

Esta "energia que brota do devaneio e do tédio", consiste, desde a ótica do autor de $O$ mau vidraceiro, em um modo de vida isolado e desvinculado de uma comunidade, na qual os laços sociais e culturais são fundados em uma possível reciprocidade, modo de vida este, em que o agir é atravessado e afetado por um certo humor; "...humor", afirma Baudelaire, "histérico segundo os médicos, satânico segundo os que pensam um pouco melhor que os médicos"(BAUDELAIRE, $1980,32)$. No entanto, o núcleo mesmo desse pequeno poema em prosa ainda 
encontra-se inacessível, ou talvez, possa nos parecer, em certa medida, paradoxal.

Antes mesmo que o devaneio e o tédio transbordassem, nos afirma o narrador da prosa de Baudelaire: "Certa manhã, levantara-me irritado, triste, fatigado de inércia, e impelido, parecia-me, a fazer algo grandioso, uma ação brilhante; e abri a janela - ai de mim!" (BAUDELAIRE, 1980, 32). Isolado em sua moradia particular, ouve "na rua" o grito de um vidraceiro, que chegou aos seus ouvidos de forma "dilacerante, dissonante, ...através da pesada e suja atmosfera parisiense"(BAUDELAIRE, 1980, 32).

Ao convidar o vidraceiro ao seu quarto no sexto andar de um prédio, para que pudesse lhe apresentar as suas mercadorias, o narrador, logo após ter percebido que dentre as mercadorias não existiam "vidros de cor", de súbito, abruptamente, por não encontrar a mercadoria capaz de preencher a sua pobreza de experiência no interior de seu refúgio arquitetônico particular, reage de maneira violenta e inesperada, como que encontrando no devaneio e no tédio o caminho para tal reação que vai de encontro ao outro, empurrando o vidraceiro escada a baixo, como demonstra este fragmento da narrativa de Baudelaire, quando do momento da apresentação das mercadorias do vidraceiro ao narrador, que se põe a questionar encoleirado:

- Como? Não tem vidros de cor? vidros róseos, vermelhos, azuis, vidros mágicos, vidros paradisíacos? Descarado! ousa andar em bairros pobres, e não tem sequer vidros que façam ver o lado belo da vida!

E empurrei-o energicamente para a escada, onde ele tropeçou, a resmungar (BAUDELAIRE, 1980, 33).

Esta narrativa do habitante urbano que retira "da pesada e suja atmosfera parisiense" a matéria narrável necessária para a sua literatura, demonstra sobretudo alguns dos traços próprios à experiência urbana moderna. Reflete antes mesmo a vivência urbana isolada e tomada pelo tédio, que na impossibilidade de vincular-se em uma tradição cultural onde possa criar laços sociais, de forma a se chocar e a recriar essa tradição, encontra na violência e todas as suas nuanças, bem como no "devaneio" do qual fala Baudelaire, o caminho através do qual surge a 
sua reação diante de uma sociedade que incorpora crescentemente a violência enquanto norma norteadora das relações políticas, culturais e de sociabilidade cotidiana.

Procurando demarcar os traços que afetam o modo de vida das grandes cidades, a perspectiva de Benjamin evoca a vida urbana como atravessada crescentemente pela "experiência do choque". Deste modo, no âmbito daquilo que podemos nomear enquanto experiência do choque, que por sua vez lembra tudo aquilo que possui a característica de passageiro, de instante com intensidade, de provisório, efêmero, inconstante, descontínuo, podemos também nomeá-la como algo que consiste sobretudo na experiência própria à multidão da cidade moderna ocidental, no que se refere à percepção sensível dos passantes acerca das paisagens urbanas bem como diante dos emblemas que nela se movem e aparecem. Estes emblemas atravessam grande parte da tradição literária que da cidade extrai sua matéria narrável, alegorias tal qual o trapeiro, a prostituta, o detetive, o vendedor ambulante, o assassino, o andarilho urbano- o flanêur -, o jogador, o operário, o mundo das mercadorias, o executivo, o mendigo, dentre outros.

Percorrendo a leitura do ensaio Sobre alguns temas em Baudelaire de Benjamin, encontramos a noção de choque ambientada sobretudo no contexto urbano sobre o qual a experiência perceptiva do habitante das grandes cidades, diante do fluxo de impressões e estímulos, aos quais à consciência está submetida na condição de choque, se articula mais precisamente ao que Benjamin demarca como o conceito de vivência. Isto indica que a noção de experiência de choque é a ante-sala da vivência, que é transformada em lírica pelo poeta/escritor. É na parte IV do ensaio que Benjamin articula o traço de choque como associado precisamente com sua noção de vivência:

Quanto maior é a participação do fator do choque em cada uma das impressões, tanto mais constante deve ser a presença do consciente no interesse em proteger contra os estímulos; quanto maior for o êxito com que ele operar, tanto menos essas impressões serão incorporadas à experiência, e tanto mais corresponderão ao conceito de vivência. Afinal, talvez seja possível ver o desempenho característico da resistência ao choque na sua função de indicar ao acontecimento, às custas da integridade de seu conteúdo, uma posição cronológica exata na 
consciência. Este seria o desempenho máximo da reflexão, que faria do incidente uma vivência (BENJAMIN, 1994, IV).

Desta maneira, Benjamin demarca como decisivo ao seu conceito de vivência, uma experiência perceptiva que preserva um interesse constante de proteção contra estímulos, diante da infinidade de estímulos externos no percurso da urbe, de tal modo que por esta condição a noção de choque não se articula com uma experiência na acepção benjaminiana, e confere à consciência um "incidente", próprio à sua noção de vivência. E quando afirmamos que a noção de choque é a ante-sala da vivência é no sentido de que o poeta, em específico Baudelaire, transforma esta experiência de choque, este "incidente", fugaz e fugidio, em uma experiência lírica:

Baudelaire inseriu a experiência do choque no âmago de seu trabalho artístico... Baudelaire abraçou como sua causa aparar os choques, de onde quer que proviessem, com seu ser espiritual e físico... A experiência do choque é uma das que se tornaram determinantes para a estrutura de Baudelaire... a íntima relação existente em Baudelaire entre a imagem do choque e o contato com as massas urbanas (BENJAMIN, 1994, IV).

Nesta direção, a experiência do choque parece marcar o modo de vida do habitante urbano, a ponto de tomarmos o choque como norma do modo de vida nas grandes cidades. No artigo Modernidade - mundo de sonho, experiência do choque, de Milena Travassos (Cadernos Walter Benjamin, 2009), encontramos esta indicação a respeito de Benjamin no que se refere à experiência de choque como condição perceptiva do habitante urbano das grandes cidades: "Benjamin constata novas maneiras de viver, sentir e perceber, constata a experiência do choque como regra para o citadino" (TRAVASSOS, 2009, 36).

Com efeito, o poema em prosa O mau vidraceiro, assim como toda a lírica de Baudelaire, preserva este movimento de tornar poético os acontecimentos do choque. No caso desta precisa referência ao poeta francês, uma das nuanças da experiência do choque desdobra-se em violência que intercepta qualquer tipo de sociabilidade, de tal modo que a prática diante do "mau vidraceiro", é ambientada enquanto uma vivência, marcada pelo choque: "E empurrei-o energicamente para a escada, onde ele tropeçou, a resmungar" (BAUDELAIRE, 1980, 33). 


\section{0 tempo da urbe moderna como transitório e fragmentário entre um cenário de alegorias fantasmagóricas: o poema "Os sete velhos de Baudelaire"}

Em um poema de Baudelaire, chamado Os sete velhos - Les sept vieillards na seção Quadros parisienses das Flores do mal, o poeta francês extrai justamente da experiência do choque, do instante com intensidade, do efêmero, do inconstante e do descontínuo, algo da ordem do eterno, ou seja, do contínuo, do imperecível, do permanente, do fixo por meio de uma poética, encontrando na obra de arte, sob a forma de poema, o caminho para exprimir algo que seja capaz de transcender a sua própria vivência desvinculada de qualquer tradição cultural, e possa através de um salto criativo, atingir gerações posteriores.

Isto é, sob a forma de escrita, o artista abre a possibilidade de transformar o passageiro e o instante com intensidade, o choque, em sublime. A expressão instante com intensidade, consiste em uma alusão à noção de experiência do choque, enunciada por Benjamin, uma vez que algo que está situado no tempo enquanto instante com intensidade, lembra algo da ordem do tempo do choque, capaz de inserir-se e chocar-se com uma modalidade histórica de memória que nem mesmo o artista supõe saber antecipadamente. Daí a intima relação entre memória, história e poética urbana. Os emblemas históricos da cidade moderna que aparecem no poema Os sete velhos, consistem nas nuanças do flanêur, isto é, no andarilho urbano embriagado e no também andarilho, o mendigo. Mas quem é este flanêur? No que, de fato, consiste a alusão à figura do mendigo?

O flanêur, ou o andarilho urbano, consiste em uma alegoria da experiência urbana moderna, que possui as suas diferenciadas variações no interior de sua unidade: "Uma dessas nuanças é a do embriagado" (OLIVEIRA, 2000, 114). Como nos indica o professor e pesquisador da obra de Benjamin, Bernardo Oliveira, em seu artigo A ótica da rua carioca: lendo Rubem Fonseca através de Benjamin e Baudelaire, nos trazendo à memória uma afirmação de Baudelaire no ensaio $O$ pintor da vida moderna, que se refere ao estado de embriaguez pelo qual é tomado 
a figura do flâneur quando este passa pela experiência de andar nas ruas da urbe: "Uma embriaguez acomete aquele que longamente vagou sem rumo pelas ruas (OLIVEIRA, 2000, 114).

Desde a ótica de Baudelaire, o âmbito de movimentação do flanêur consiste antes de tudo na multidão própria à vida urbana, "pois para o perfeito flanêur, para o observador apaixonado, é um imenso júbilo fixar residência no numeroso, no ondulante, no movimento, no fugidio e no infinito"(BAUDELAIRE, 1988, 173). E é justamente o andarilho urbano embriagado o poeta de Os sete velhos de Baudelaire, que se vê na condição de "Bêbado que vê dois, assim exasperado" ${ }^{8}$ (BAUDELAIRE, 2001, 103).

Embriagado de choques urbanos, este, que passa pela experiência comum aos passantes do solo urbano, enquanto experiência do choque, abre a possibilidade de "extrair o eterno do transitório"(BAUDELAIRE, 1988, 173), a qual se refere o poeta de Os sete velhos. Extrai, portanto, do efêmero, do inconstante, do transitório, e sobretudo do instante com intensidade, a matéria narrável de seu exprimir poético, digno de registro pelo poeta, e capaz de criar um fio de continuidade no raio histórico do que nomeamos enquanto experiência urbana moderna, pois como afirma o próprio Baudelaire, em seu ensaio 0 pintor da vida moderna: "Poucos homens são dotados da faculdade de ver; há ainda menos homens que possuem a capacidade de exprimir". Significa, por extensão, extrair o poético do histórico, pois como assegura o poeta francês "toda a nossa originalidade vem da inscrição que o tempo imprime às nossas sensações" (BAUDELAIRE, 1988, 176).

No cenário do poema de Baudelaire Os sete velhos, perambulando a esmo pelas ruas da "Fourmillante cité", o andarilho urbano embriagado de choques próprios da vida citadina, certa manhã na "triste rue" caminhando por entre "la brume", juntamente com seus "nerfs comme un héros", de súbito vê diante de si um "vieillard", cujo semblante no que se refere à sua fisionomia e indumentária, apresenta um aspecto decrépito. Assim o descreve o poeta, na tradução de Duda Machado para a Revista Zunái:

8 "Exaspéré comme un ivrogne qui voit double" (Les sept vieillards, Baudelaire). 
Súbito, um velho num remendo amarelado,

Que a cor do céu chuvoso vinha duplicar,

Desses que atrai esmolas pelo seu estado, Não fosse o brilho de maldade em seu olhar,

Surgiu. Sua pupila vinha mergulhada Em fel; seus olhos tinham lâminas agudas

De geada, e a barba dura como espada Se projetava idêntica a que foi de Judas $^{9}$

Com efeito, tal aspecto reflete a alegoria do ser humano afetado historicamente por uma sociedade assentada em desigualdades sociais radicais, sobrevivendo, contudo, na condição de esquecimento e deformidade, apresentando um semblante de todo deformado e decrépito, amarelo tal qual o sol que o expõe aos olhos do embriagado andarilho que o vê ao dobrar uma esquina. Aspecto este traçado no percurso de uma vida que persiste e resiste historicamente sob a condição "Desses que atrai esmolas pelo seu estado, Não fosse o brilho de maldade em seu olhar", como o afirma Baudelaire - Alegoria da vida urbana moderna que deixa rastros e vestígios grotescos que sucumbem na identificação da ruína à qual estão sujeitos aqueles, agora velhos, com imagem gasta pelo tempo e hostis aos olhos dos passantes. Velhos das gerações anteriores, que persistem e perduram em tal solo urbano sob a condição de esquecimento e deformação, quando da oportunidade da descrição pelo andarilho embriagado, em relação ao aspecto do outro que de súbito aparece diante de seus olhos:

Mais que curvo, partido desde o espinhaço

Até a perna num ângulo reto perfeito, De tal jeito que o seu bastão, fechando o traço,

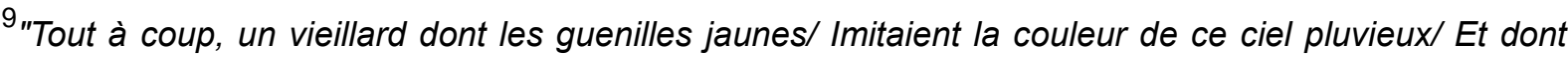
l'aspect aurait fait pleuvoir les aumônes/ Sans la méchanceté qui luisait dans ses yeux/ M'apparut. On eût dit sa prunelle trempée/ Dans le fiel; son regard aiguisait les frimas/ Et sa barbe à longs poils, roide comme une épée/ Se projetait, pareille à celle de Judas" (Les sept vieillards, Baudelaire).
} 
Dava à sua figura e seu andar o efeito ${ }^{10}$

Como se não bastasse o olhar do andarilho embriagado diante da assustadora imagem do velho andarilho mendigo - alegoria da ruína de gerações anteriores que ainda persiste e perdura na vida urbana moderna - outros sete velhos tais quais o primeiro, aparecem-lhe de súbito, apresentando pois o retorno do mesmo aspecto decrépito, bem como "do mesmo inferno saído". As novas imagens, ou antes mesmo, os novos corpos, aparecem como já decadentes e sobretudo com o destino desconhecido:

Vinha com seu par: barba, olhar, costas, cajados, Gêmeos em tudo, do mesmo inferno saído, Espectros tão antigos quanto amaneirados A seguir para o mesmo fim desco/nhecido. Em que complô infame eu tinha me enredado Ou que acaso perverso tanto me humilhava? Pois contei sete vezes devagar, pausado Que este velho sinistro se multiplicava!

Em que complô infame eu tinha me enredado Ou que acaso perverso tanto me humilhava? Pois contei sete vezes devagar, pausado Que este velho sinistro se multiplicava! ${ }^{11}$

Tais alegorias do "enfer" enunciadas por Baudelaire, demonstram que um dos principais traços do raio histórico da experiência urbana moderna, consiste

10"Il n'était pas voûté, mais cassé, son échine/ Faisant avec sa jambe un parfait angle droit/ Si bien que son bâton, parachevant sa mine/ Lui donnait la tournure et le pas maladroit"(Les sept vieillards, Baudelaire).

11 "Son pareil le suivait: barbe, oeil, dos, bâton, loques/ Nul trait ne distinguait, du même enfer venu/ Ce jumeau centenaire, et ces spectres baroques/ Marchaient du même pas vers un but inconnu/ $A$ quel complot infâme étais-je donc en butte/ Ou quel méchant hasard ainsi m'humiliait?/ Car je comptai sept fois, de minute en minute/ Ce sinistre vieillard qui se multipliait!/ Que celui-là qui rit de mon inquiétude/ Et qui n'est pas saisi d'un frisson fraternel/ Songe bien que malgré tant de décrépitude/ Ces sept monstres hideux avaient l'air éternel!" (Les sept vieillards, Baudelaire). 
justamente nos vestígios da ruína na qual se transformou a cidade contemporânea, cidade esta que ainda perdura sem que as gerações anteriores tenham desviado do caminho que sucumbe na própria ruína. "Ou que acaso perverso tanto me humilhava?"12, questiona-se subitamente o embriagado andarilho que logo pela manhã passa pela experiência própria aos habitantes da cidade, enquanto experiência do choque, do instante com intensidade, e no entanto, esclarecedor e marcante no que se refere à condição histórica da cidade contemporânea.

No entanto, tais emblemas da ruína histórica da cidade fazem o andarilho embriagado oscilar circunstancialmente entre a rua e seu refúgio arquitetônico particular, sendo este o espaço necessário para o distanciamento do "enfer" do qual fala Baudelaire, encontrando em sua moradia, o isolamento da vida urbana inquietante e perturbadora, e que sobretudo, o acompanha em sua memória fragmentária. É a vivência urbana pobre em experiências comunicáveis e que o atordoa com a condição histórica da cidade moderna em forma de ruína, na qual são emblemas o aspecto decrépito dos sete velhos, distancia-se rumo à sua moradia individual após o instante com intensidade na condição do choque benjaminiano, que a pouco pôde presenciar na rua em que passava, e que embriagado afirma:

Irritado, qual bêbedo que vê em dobro, Tranquei-me em casa, atônito, longe de tudo, Hirto, febril, com a alma doente de logro, Dilacerado pelo mistério e o absurdo!

Minha razão queria sustentar a vela; Mas de nada valia contra o temporal, E minha alma dançava, antiga caravela Num mar medonho, sem mastros, sem litoral! ${ }^{13}$

\footnotetext{
12"Ou quel méchant hasard ainsi m'humiliait?" (Les sept vieillards, Baudelaire).

13 "Exaspéré comme un ivrogne qui voit double/Je rentrai, je fermai ma porte, épouvanté/ Malade et morfondu, l'esprit fiévreux et trouble/ Blessé par le mystère et par l'absurdité!/ Vainement ma raison voulait prendre la barre/ La tempête en jouant déroutait ses efforts/ Et mon âme dansait, dansait, vieille gabarre/ Sans mâts, sur une mer monstrueuse et sans bords!" Tradução de Duda Machado, para a Revista Zunái. URL:
} 


\section{REFERÊNCIAS}

BENJAMIN, W. Obras escolhidas v. I: Magia e técnica, arte e política.

Ensaios sobre literatura e história da cultura. Trad. Sérgio Paulo Rouanet. São Paulo: Brasiliense, 1985.

Obras escolhidas v. III: Charles Baudelaire: um lírico no auge

do capitalismo. Trad. José Carlos Barbosa e Hemerson Alves Baptista. São Paulo: Brasiliense, 1994.

BAUDELAIRE, C. As flores do mal. Trad. Pietro Nassetti. São Paulo: Martin Claret, 2001.

Pequenos poemas em prosa. Trad. de Aurélio B. de Holanda.

Rio: Nova Fronteira, 1980.

O pintor da vida moderna. A modernidade de Baudelaire.

Rio de Janeiro, Paz e Terra, 1988.

. Les sept vieillards/ Os sete velhos. Trad. Duda Machado.

Revista Zunái, 2005.

OLIVEIRA, B. "A ótica da rua carioca: lendo Rubem Fonseca através de Benjamin e Baudelaire." in:__Alea: Estudos Neolatinos. Rio de janeiro: Faculdade de Letras da UFRJ, 2000.

TEODORO, J. "As imagens da modernidade nos 'Quadros Parisienses' de Baudelaire e a relação com o caderno 'J-Baudelaire' de projeto das Passagens" in:

Cadernos Walter Benjamin, Periódico n. 9, www.gewebe.com.br, 2012.

CLARINVAL, O. "La mémoire de I'histoire chez Proust et Benjamin" in:_ The French Review. Vol. 82, No. 5, 2009.

TRAVASSOS, "M. Modernidade - mundo de sonho, experiência do choque." In:_Cadernos Walter Benjamin, Periódico n. 3, www.gewebe.com.br, 2009.

http://www.revistazunai.com/traducoes/charles_baudelaire.htm 